\title{
PENGARUH TRUST DAN E-SERVICE QUALITY TERHADAP KEPUTUSAN PEMBELIAN DI ONLINE SHOP SHOPEE (Studi pada Mahasiswa Fakultas Ekonomi dan Bisnis Universitas Singaperbangsa Karawang)
}

\author{
Danang Kusnanto \\ Fakultas Ekonomi dan Bisnis, Universitas Singaperbangsa Kerawang \\ Email: danang.kusnanto@fe.unsika.ac.id \\ Rida Rahma \\ Fakultas Ekonomi dan Bisnis, Universitas Singaperbangsa Karawang \\ Email: ridarahma30@gmail.com \\ Riska Ayu Oktaviany \\ Fakultas Ekonomi dan Bisnis, Universitas Singaperbangsa Karawang \\ Email: riskaoktaviany13@gmail.com
}

DOI: http://dx.doi.org/10.35908/jeg.v5i1.912

\begin{abstract}
As for the purpose, to obtain empirical evidence and find clarity phenomena and conclusions about The Effect of Trust and E-Service Quality to Buying Decision in Online Shop Shopee at Economy and Business Faculty University of Singaperbangsa Karawang. The study was conducted by using desciptive and verification methods, such as collecting, presenting, analyzing, and testing hypothesis, and made conclusions and suggestions. Sample were collected by using Stratified Random Sampling and Purposive sampling methods with a sample od 100 respondensfrom a population of 3.597 people. The data analysis technique was used Bar Scale Analysis technique and Path Analysis by using Method Succesive Interval, Microsoft Office Excel 2010, and SPSS. Based on the research result trust variable $(X 1)$ has a significant effect of buying decision $(Y)$ with a percentage of 53,1\%, which means that further increasing trust consumer will increase buying decisions to the product offered. E-service qualiy (X2) has a significant effect on buying decision $(Y)$ with a persentage of $15,1 \%$, which means that e-service quality effect the rentention of customers. There is a simultaneous effect of trust and e-service quality variables on buying decision by $68,2 \%$ and the remaining $31,8 \%$ is influenced by other variables not examined in this study.
\end{abstract}

Keywords: Trust, E-Service Quality, Buying Decision

\begin{abstract}
ABSTRAK
Tujuan penelitian, untuk memperoleh bukti-bukti empirik dan menemukan kejelasan fenomena serta kesimpulan tentang Pengaruh Trust dan E-Service Quality terhadap Keputusan Pembelian di Online Shop Shopee pada Mahasiswa Fakultas Ekonomi dan Bisnis Universitas Singaperbangsa Karawang. Penelitian ini dilakukan dengan menggunakan metode deskriptif dan verifikatif, yaitu mengumpulkan, menyajikan, menganalisis, melakukan pengujian hipotesis, serta membuat kesimpulan dan saran. Sampel dikumpulkan dengan menggunakan metode Stratified Random Sampling dan Purposive Sampling dengan jumlah sampel sebanyak 100 responden dari populasi 3.597 orang. Teknik analisis data yang digunakan yaitu teknik analisis rentang skala dan analisis jalur dengan bantuan Methode Succesive Interval, Microsoft Office Excel 2010, dan SPSS. Berdasarkan hasil penelitian variabel trust (X1) berpengaruh signifikan terhadap keputusan pembelian (Y) dengan persentase sebesar 53,1\%, yang berarti semakin meningkatkan kepercayaan kepada konsumen akan meningkatkan keputusan pembelian pada produk yang ditawarkan. E-service quality (X2) berpengaruh signifikan terhadap keputusan pembelian (Y) dengan persentase 15,1\%, yang berarti e-service quality mempengaruhi mempertahankan pelanggan agar tidak beralih ketempat lain. Terdapat pengaruh simultan variabel trust dan e-service quality terhadap keputusan pembelian sebesar $68,2 \%$ dan sisanya $31,8 \%$ dipengaruhi oleh variabel lain yang tidak diteliti dalam penelitian ini.
\end{abstract}

Kata Kunci: Kepercayaan, Pelayanan Online, Keputusan Pembelian 


\section{Pendahuluan}

Pesatnya perkembangan industri $e$ commerce, khususnya di Indonesia semakin memacu persaingan antara para pelaku bisnis di dunia maya. Shopee merupakan salah satu online shop terbaik yang ada di Indonesia. Shopee adalah suatu perusahaan yang menyediakan fasilitas untuk penjual mengelola toko secara online dan juga sebagai tempat untuk bertemunya penjual dan pembeli tanpa perlu tatap muka secara langsung.

Disisi lain dengan bertambahnya vendor online shop di Indonesia tidak serta merta membuat masyarakat Indonesia semakin nyaman dan mudah dalam berbelanja via online. Hal ini dikarenakan adanya indikasi kecurangan atau penipuan dari oknum-oknum online shop yang tidak betanggungjawab, inilah yang menyebabkan adanya keraguan di masyarakat Indonesia dan ini juga yang menyebabkan kenapa transaksi melalui online shop disebut memiliki potensi resiko yang sukup tinggi.

Oleh karena itu, memberikan Trust pada pelanggan merupakan suatu upaya yang dilakukan oleh vendor agar konsumen bisa yakin terhadap online shop dan hasilnya bisa menciptakan keputusan pembelian konsumen, serta e-service quality berpengaruh positif dan signifikan dalam meningkatkan minat beli membeli atau keputusan pembelian.

Berdasarkan latar belakang masalah, maka rumusan masalah dalam penelitian ini sebagai berikut:

1. Bagaimana trust Mahasiswa Fakultas Ekonomi dan Bisnis Universitas Singaperbangsa Karawang pada Online Shop Shopee?

2. Bagaimana e-service quality Mahasiswa Fakultas Ekonomi dan
Bisnis Universitas Singaperbangsa Karawang pada Online Shop Shopee?

3. Bagaimana keputusan pembelian Mahasiswa Fakultas Ekonomi dan Bisnis Universitas Singaperbangsa Karawang pada Online Shop Shopee?

4. Seberapa besar hubungan antara trust dengan e-service quality Online Shop Shopee pada Mahasiswa Fakultas Ekonomi dan Bisnis Universitas Singaperbangsa Karawang?

5. Seberapa besar pengaruh parsial trust terhadap keputusan pembelian dan $e$ service quality terhadap keputusan pembelian Mahasiswa Fakultas Ekonomi dan Bisnis Universitas Singaperbangsa Karawang pada Online Shop Shopee?

6. Seberapa besar pengaruh simultan trust dan e-service quality terhadap keputusan pembelian Mahasiswa Fakultas Ekonomi dan Bisnis Universitas Singaperbangsa Karawang pada Online Shop Shopee?

Berdasarkan latar belakang dan rumusan masalah tersebut, penelitian ini bertujuan sebagai berikut:

1. Untuk mengetahui, menganalisis, dan menjelaskan trust Mahasiswa Fakultas Ekonomi dan Bisnis Universitas Singaperbangsa Karawang pada Online Shop Shopee.

2. Untuk mengetahui, menganalisis, dan menjelaskan e-service quality Mahasiswa Fakultas Ekonomi dan Bisnis Universitas Singaperbangsa Karawang pada Online Shop Shopee.

3. Untuk mengetahui, menganalisis, dan menjelaskan keputusan pembelian Mahasiswa Fakultas Ekonomi dan 
Bisnis Universitas Singaperbangsa Karawang pada Online Shop Shopee.

4. Untuk mengetahui, menganalisis, dan menjelaskan hubungan trust dan $e$ service quality Mahasiswa Fakultas Ekonomi dan Bisnis Universitas Singaperbangsa Karawang pada Online Shop Shopee.

5. Untuk mengetahui, menganalisis, dan menjelaskan pengaruh parsial trust dan e-service quality Mahasiswa Fakultas Ekonomi dan Bisnis Universitas Singaperbangsa Karawang pada Online Shop Shopee.

6. Untuk mengetahui, menganalisis, dan menjelaskan pengaruh simultan trust dan e-service quality Mahasiswa Fakultas Ekonomi dan Bisnis Universitas Singaperbangsa Karawang pada Online Shop Shopee.

\section{Trust}

Menurut Dunn (2004: 66) menyatakan bahwa "Trust is an intangible characteristic that allows customers to buy goods or service with the confidence that what is promised will be delivered". Artinya kepercayaan merupakan karakteristik yang tidak nampak, yang mengizinkan pelanggan untuk mebeli produk dan jasa dengan keyakinan bahwa apa yang dijanjikan akan ditepati. Trust atau kepercayaan telah dipertimbangkan sebagai katalis dalam berbagai transaksi antara penjual dan pembeli agar kepuasan konsumen dapat terwujud sesuai dengan yang diharapkan (Yousafzai et al, 2003). Sedangkan Gafen (2000) mendefinisikan trust adalah kemauan untuk membuat dirinya peka terhadap tindakan yang diambil oleh orang yang dipercayainya berdasarkan pada rasa kepercayaan dan tanggungjawab.
E-Service Quality

Menurut Perasuraman dalam Lupiyoadi (2001:148), E-Service Quality adalah "sebagai seberapa jauh perbedaan antara kenyataan dan harapan pelanggan atas layanan yang mereka terima dan diperoleh" Perasuraman, dkk. (2005) menyatakan definisi kualitas layanan online dalam interaksinya dengan website adalah "the extent to which a website facilities efficient and effective shopping, purchasing and delivery". Penjelasan definisi diartikan sebagai suatu tingkat sebuah website secara efektif dan efisien memfasilitasi dalam hal berbelanja, melakukan pembelian dan proses penyerahan dari produk dan jasa. Penilaian kualitas website tdiak hanya saat pengalaman selama melakukan interaksi dengan website, tetapi juga interaksi setalah mndapatkan layanan. Sedangkan Menurut (Bressolles \& Durrieu,2011), berbeda dengan system pelayanan tradisional dimana yang ditawarkan adalah kemudahan untuk mendapatkan informasi antar konsumen dengan penyedia layanan yang berbasis elektronik.

\section{Keputusan Pembelian}

Menurut Buchari Alma (2011:96), mengemukakan bahwa keputusan pembelian adalah : "Suatu keputusan konsumen yang dipengaruhi oleh ekonomi keuangan, teknologi, politik, budaya, produk, harga, lokasi, promosi, physical evidence, people dan process, sehingga membentuk suatu sikap pada konsumen untuk mengolah segala informasi dan mengambil kesimpulan berupa response yang muncul produk apa yang akan dibeli”.

Sedangkan Menurut Philip Kotler 
yang diterjemahkan oleh A.B Susanto (2012 : 202) mengemukakan bahwa keputusan pembelian dapat diartikan sebagai suatu keputusan yang diambil oleh seorang calon pembeli menyangkut kepastian akan membeli atau tidak.

Pembelian merupakan suatu keputusan yang dipengaruhi oleh beberapa faktor yang akan membuat konsumen secara aktual mempertimbangkan segala sesuatu dan pada akhirnya konsumen membeli produk yang paling mereka sukai.

Berdasarkan latar belakangan di atas maka penulis tertarik untuk meneliti dengan judul: "Pengaruh Trust dan EService Quality terhadap di Online Shop Shopee pada Mahasiswa Fakultas Ekonomi dan Bisnis Universitas Singaperbangsa Karawang”.

\section{Metode Penelitian}

Sampel dikumpulkan dengan menggunakan metode Stratified Random Sampling dan Purposive Sampling dengan jumlah sampel sebanyak 100 responden dari populasi 3.597 orang.

Jenis data yang digunakan dalam penelitian ini ada dua yaitu, data primer yaitu data asli yang dikumpulkan oleh peneliti untuk menjawab masalah yang ada dan data sekunder yaitu data yang sudah tersedia dan dikumpulkan oleh pihak lain.

Pada penelitian ini menggunakan metode pengumpulan data dengan survei, kuesioner, dan penelusuran literatur untuk mendapatkan data dan informasi langsung dari Mahasiswa Fakultas Ekonomi dan Bisnis Universitas Singaperbangsa Karawang.

Penelitian ini dilakukan dengan menggunakan metode deskriptif dan verifikatif. Analisis deskriptif yaitu suatu metode pengumpulan untuk memperoleh bahan-bahan teoritis yang dapat dijadikan dasar bagi pengkajian masalah. Melalui penelitian ini penulis mempelajari bukubuku dan lainnya yang ada hubungannya dengan masalah yang dibahas, baik secara langsung maupun tidak langsung. Teknis deskriptif yang memberikan informasi mengenai data yang dimiliki dan tidak termasuk menguji hipotesis.

Analisis ini hanya digunakan untuk menyajikan dan menganalisis data disertai dengan perhitungan agar dapat memperjelas keadaan atau karakteristik data yang bersangkutan, pengukuran yang digunakan dalam penelitian ini dalah mean, standar deviasi, maksimum, dan minimum. Mean digunakan untuk mengetahui rata- rata data.

Analisis verikatif bermaksud untuk mengetahui hasil penelitian yang berkaitan dengan Pengaruh trust dan $e$ service quality terhadap Keputusan Pembelian di Online Shop Shopee pada Mahasiswa Fakultas Ekonomi dan Bisnis Universitas Singaperbangsa Karawang.

Teknik analisis data yang digunakan yaitu teknik analisis rentang skala dan analisis jalur dengan bantuan Methode Succesive Interval, Microsoft Office Excel 2010, dan SPSS.

Variabel penelitian yang digunakan trust $\left(\mathrm{x}_{1}\right)$ menggunakan dimensi yang dikemukakan oleh Mayor et al (1995) yaitu kemampuan, kebaikan hati, dan integritas. Variabel e-service quality $\mathrm{x}_{2}$ ) menggunakan dimensi yang dikemukakan oleh Tjiptono dan Chandra (2007:171-173) yaitu efisiensi, reliabilitas, fulfillment, privasi, data tanggung, kompensasi dan kontak. Variabel keputusan pembelian (Y) menggunakan dimensi yang 
dikemukakan oleh Kotler dan Armstrong (2012:188) yaitu pilihan produk, pilihan merek, pilihan penyalur, jumlah pembeli, waktu pembelian, dan metode pembayaran.

\section{Pembahasan}

Karakteristik Responden Hasil analisis karakteristik responden berdasarkan kelompok jenis kelamin mayoritas responden perempuan sebanyak 60 dengan persentase $60 \%$ dan laki-laki sebanyak 40 dengan persentase $40 \%$. Berdasarkan usia responden dibawah usia 25 tahun sebanyak 96 dengan persentase 96\% dan usia diatas 25 tahun sebanyak 4 dengan persentase 4\%. Responden berdasarkan jumlah uang saku $<\mathrm{Rp}$ 1.000.000,- sebanyak 71 dengan persentase $71 \%$ dan $>\mathrm{Rp} 1.00 .000$,sebanyak 29 dengan persentase $29 \%$.

\section{Hasil Uji Asumsi Klasik}

\section{Uji Validitas}

Berdasarkan uji validitas variabel trust, $e$ - service quality, dan keputusan pembelian dengan 30 pernyataan di dalam kuesioner memiliki $r$ hitung diatas 0,30 atau $r$ hitung > r kritis, maka semua pernyataan kuesioner variabel trust, e-service quality, dan keputusan pembelian dinyatakan valid.

Uji Reliabilitas

Tabel 1. Tabel Hasil Uji Reliabilitas

\begin{tabular}{|l|c|c|c|}
\hline \multicolumn{1}{|c|}{ Variabel } & $\mathbf{r}_{\text {hitung }}$ & $\mathbf{r}_{\text {kritis }}$ & Kriteria \\
\hline Trust $\left(\mathrm{X}_{1}\right)$ & 0,915 & 0,60 & Reliabel \\
\hline E-Service Quality $\left(\mathrm{X}_{2}\right)$ & 0,896 & 0,60 & Reliabel \\
\hline Keputusan Pembelian & 0,922 & 0,60 & Reliabel \\
\hline
\end{tabular}

Sumber : data dioleh spps, peneliti 2019

Berdasarkan data pada tabel 3.1 bahwa hasil uji reliabilitas setiap variabel memiliki $\mathrm{r}_{\text {hitung }}>\mathrm{r}_{\text {kritis }}$ maka seluruh variabel dinyatakan reliabel.
Uji Normalitas

Berdasarkan hasil uji normalitas variabel trust $\left(\mathrm{x}_{1}\right)$, e-service quality $\left(\mathrm{x}_{2}\right)$, dan keputusan pembelian mengikuti sebaran data normal karena signifikan $\alpha$ hitung semua variabel lebih dari 0,05 , maka semua variabel berdistribusi secara normal.

Uji Analisis Regresi Linear Berganda Uji regresi berganda digunakan untuk mengetahui pengaruh atau hubungan secara linier antara dua atau lebih variabel independen dengan satu variabel dependen.

Tabel 2. Tabel Hasil Uji Analisis Regresi Linier Berganda

\begin{tabular}{|c|c|c|c|c|c|c|}
\hline \multirow{2}{*}{\multicolumn{2}{|c|}{ Model }} & \multicolumn{2}{|c|}{$\begin{array}{c}\text { Unstandardized } \\
\text { Coefficients }\end{array}$} & \multirow{2}{*}{$\begin{array}{c}\text { Stan } \\
\text { dardi } \\
\text { zed } \\
\text { Coeff } \\
\text { icien } \\
\text { ts } \\
\text { Beta }\end{array}$} & \multirow[t]{2}{*}{$T$} & \multirow[t]{2}{*}{ Sig. } \\
\hline & & $B$ & $\begin{array}{c}\text { Std. } \\
\text { Error }\end{array}$ & & & \\
\hline 1 & $\begin{array}{l}\text { (Con } \\
\text { stant })\end{array}$ & 5,857 & 2,170 & & 2,699 & ,008 \\
\hline & Trust & ,673 & ,110 & 649 & 6,144 & ,000 \\
\hline & \begin{tabular}{l}
\multicolumn{1}{c}{ E- } \\
Servi \\
ce \\
Quali \\
ty
\end{tabular} & ,216 & ,112 & ,203 & 1,926 & ,057 \\
\hline
\end{tabular}

Adapun bentuk persamaan dari perhitungan nilai regresi dari tabel 3.2 sebagai berikut:

$$
Y=0,649 X_{1}+0,203 X_{2}+€
$$

Interprestasi persamaan regresi sebagai berikut :

1. Adanya hubungan antara trust $\left(\mathrm{x}_{1}\right)$ terhadap keputusan pembelian (Y) sebesar 0,649.

2. Adanya hubungan antara e-service quality $\left(\mathrm{X}_{2}\right)$ terhadap keputusa 
pembelian (Y) sebesar 0,203.

Tabel 3. Koefisien Determinasi

\begin{tabular}{|c|c|c|c|c|}
\hline Model & $\mathrm{R}$ & $\mathrm{R}$ Square & $\begin{array}{c}\text { Adjusted } \mathrm{R} \\
\text { Square }\end{array}$ & $\begin{array}{c}\text { Std. Error } \\
\text { of the } \\
\text { Estimate }\end{array}$ \\
\hline 1 &, $827^{\mathrm{a}}$ & 0,684 & 0,678 & 3,99674 \\
\hline
\end{tabular}

a. Predictors: (constant), $\mathrm{X}_{1}, \mathrm{X}_{2}$

b. Dependent Variable: Keputusan Pembelian

$$
\begin{aligned}
& p \epsilon=\sqrt{1-r^{2}} \\
& p \epsilon=\sqrt{1-0,684} \\
& =0,316
\end{aligned}
$$

Tabel 4. Pengaruh Langsung dan Tidak Langsung

\begin{tabular}{|r|r|r|r|r|l|}
\hline \multirow{2}{*}{ Variabe 1 } & \multirow{2}{*}{$\begin{array}{c}\text { Koefisien } \\
\text { Jalur }\end{array}$} & $\begin{array}{c}\text { Pengaruh } \\
\text { Langsung }\end{array}$ & \multicolumn{2}{|c|}{$\begin{array}{c}\text { Pengaruh } \\
\text { tidak } \\
\text { langsung }\end{array}$} & \multirow{2}{*}{$\begin{array}{c}\text { Sub total } \\
\text { pengaru h }\end{array}$} \\
\cline { 1 - 5 } $\mathrm{X}_{1}$ & 0,649 & 0,421 & - & 0,111 & 0.532 \\
\hline $\mathrm{X}_{2}$ & 0,203 & 0,041 & 0,111 & - & 0,152 \\
\hline \multicolumn{7}{|c|}{ Total } & & 0,684 \\
\hline $\boldsymbol{\epsilon}$ & 0,316 & 0,318 & - & - & 0,316 \\
\hline
\end{tabular}

Berdasarkan tabel diatas dapat dijelaskan bahwa :

1. Pengaruh langsung variabel $\mathrm{X}_{1}$ terhadap Y sebesar $42,1 \%$

2. Pengaruh langsung variabel $\mathrm{X}_{2}$ terhadap Y sebesar 4,1\%

3. Pengaruh tidak langsung variabel $\mathrm{X}_{1}$ dan $\mathrm{X}_{2}$ terhadap $\mathrm{Y}$ sebesar $11,1 \%$

4. Pengaruh parsial variabel $\mathrm{X}_{1}$ terhadap Y sebesar 53,2\%

5. Pengaruh parsial variabel $\mathrm{X}_{2}$ terhadap Y sebesar $15.2 \%$

6. dan Pengaruh simultan antara variabel $\mathrm{X}_{1}$ dan $\mathrm{X}_{2}$ terhadap $\mathrm{Y}$ adalah sebesar $68,4 \%$ sedangkan pengaruh variabel lain adalah sebesar $31,6 \%$.

Pengujian Hipotesis

Uji t digunakan untuk mengetahui apakah secara parsial variabel trust dan variabel e-service quality berpengaruh secara signifikan atau tidak terhadap variabel keputusan pembelian.

Menentukan $t_{\text {tabel }}$ dapat dilihat pada tabel statistik pada signifikansi dengan derajat kebebasan $\mathrm{df}=\mathrm{n}-2$ atau $100-2=$ 98, hasil diperoleh untuk $t_{\text {tabel }}$ sebesar 1,660 .

Hipotesis 1

Dapat dilihat dari tabel bahwa nilai $t_{\text {hitung }}>\mathrm{t}_{\text {tabel }}(6,144>1,660)$ dan signifikansi $(0,057)<\alpha(0,10)$ maka $\mathrm{H}_{1}$ diterima, jadi dapat disimpulkan bahwa variabel trust $\left(\mathrm{X}_{1}\right)$ secara parsial berpengaruh signifikan terhadap keputusan pembelian (Y) pada online shop shopee.

Hipotesis 2

Dapat dilihat dari tabel bahwa nilai $t_{\text {hitung }}>\mathrm{t}_{\text {tabel }}(1,926>1,660)$ dan signifikansi $(0,000)<\alpha(0,10)$ maka $\mathrm{H}_{2}$ diterima, jadi dapat disimpulkan bahwa variabel e-service quality $\left(\mathrm{X}_{2}\right)$ secara parsial berpengaruh signifikan terhadap keputusan pembelian (Y) pada online shop shopee.

\section{Hasil Uji Sgnifikan F}

Uji $F$ digunakan untuk menguji signifikansi secara simultan antara variabel independen yaitu variabel trust $\left(\mathrm{X}_{1}\right)$ dan variabel e-service quality $\left(\mathrm{X}_{2}\right)$ terhadap variabel keputusan pembelian (Y).

Menentukan $\mathrm{F}$ tabel dapat dilihat pada tabel statistic pada tingkat signifikansi 0,10 dengan df 1 (jumlah varibel -1$) \rightarrow 2$ dan df $2(\mathrm{n}-\mathrm{k}-1)$ atau $100-2-1=97$ dimana $n$ adalah jumlah data $\mathrm{k}$ adalah jumlah variabel independen, hasil diperoleh untuk $\mathrm{F}_{\text {tabel }}$ sebesar 2,36.

Hipotesis 3 
Berdasarkan tabel diatas, diketahui bahwa $F_{\text {hitung }}>F_{\text {tabel }}(105,902>2,36)$ dan signifikansi $<\alpha(0,000<0,10)$ maka hipotesis 3 diterima, jadi dapat disimpulkan bahwa variabel trust $\left(\mathrm{X}_{1}\right)$ dan variabel e-service quality $\left(\mathrm{X}_{2}\right)$ secara bersama-sama (simultan) berpengaruh signifikansi terhadap keputusan pembelian pada online shop shopee.

\section{Kesimpulan}

Berdasarkan hasil penelitian dan pembahasan diatas:

1. Dari hasil analisis diperoleh bahwa, variabel trust memiliki koefisien regresi sebesar 0,649 (bertanda positif) dengan angka signifikansi $0,000(<0,10)$. Dengan demikian menunjukkan bahwa trust berpengaruh positif dan signifikan terhadap keputusan pembelian.

2. Dari hasil analisis diperoleh bahwa, variabel e-service quality memiliki koefisien regresi sebesar 0,203 (bertanda positif) dengan angka signifikansi $0,000(<0,10)$. Dengan demikian menunjukkan bahwa $e$ service quality berpengaruh positif dan signifikan terhadap keputusan pembelian.

3. Dari hasil analisis untuk trust dan eservice quality memiliki pengaruh yang besar, dilihat dari koefisien regresinya untuk trust sebesar 64,9\% dan e-service quality 20,3\%. Dengan demikian menunjukkan bahwa variabel trust memiliki pengaruh yang lebih besar dibandingkan dengan harga terhadap keputusan pembelian di online shop shopee.
Saran

1. trust menjadi topic utama dalam menciptakan keputusan pembelian. Trust pada online shop shopee sudah baik dimata konsumen. Meski demikian pihak online shop shopee sebaiknya terus meningkatkan trust agar lebih baik.

2. diharapkan pihak online shop shopee dapat mengevaluasi kembali e-service quality yang telah dilakukan agar menjadi lebih baik lagi dalam pelayanan kepada konsumen.

\section{DaftarPustaka}

Alma, Buchari. 2013. Manajemen Pemasaran dan Pemasaran Jasa. CV Alfabeta. Bandung.

Aziz, A.M. dan Irjayanti, M. 2014. Manajemen. Mardika Group. Bandung.

Dewi, Irra Chrisyanti. 2011. Manajemen Kesekretariatan. Cetakan Pertama. PT Prestasi Pustakaraya. Jakarta.

Hasibuan, Malayu S.P. 2011. Manajemen: Dasar, Pengertian, dan Masalah. PT Aksara. Jakarta.

Hasibuan, Malayu S.P. 2014. Manajemen: Dasar, Pengertian, dan Masalah, Edisi Revisi Cetakan Kesepuluh. PT Bumi Aksara. Jakarta.

Kotler, Philip. 2000. Manajemen Pemasaran, Edisi Milenium Jilid 1 \& 2. PT Prenhalindo. Jakarta.

Kotler, Philip and Armstrong, Gary. 2008. Prinsip-prinsip Pemasaran, Edisi 12 Jilid 1 PT Erlangga. Jakarta.

Kotler, Philip dan Keller, K.L 2008. Manajemen Pemasaran, Edisi 13 Jilid 1 PT Erlangga. Jakarta.

Kotler, Philip dan Keller, K.L 2008. Manajemen Pemasaran, Edisi 13 Jilid 1 PT Erlangga. Jakarta. 
Kotler, Philip dan Keller, K.L 2009. Manajemen Pemasaran, Edisi 13 Jilid 1 PT Erlangga. Jakarta.

Kotler, Philip dan Keller, K.L 2013. Manajemen Pemasaran, Edisi 13 Jilid 1 PT Erlangga. Jakarta.

Sugiyono. 2015. Metode Penelitian Kuantitatif dan $R \& D . \quad \mathrm{CV}$ Alfabeta. Bandung.

Sumarwan, Ujang. 2011. Perilaku Konsumen. Ghalia Indonesia.
Bogor.

Sutopo, Yeri. 2017. Statistika Inferensial. CV Andi Offset. Yogyakarta.

Tjiptono, Fandy dan Candra, Gregorius. 2007. Service Quality \& Satisfaction, Edisi Kedua. Andi. Yogyakarta.

Tjiptono, Fandy. 2007. Strategi Pemasaran, Edisi Kedua. Andi. Yogyakarta. 